\title{
UMA ANALOGIA ENTRE A LOGÍSTICA REVERSA, ISO 14000, E A POLÍ́TICA NACIONAL DE RESÍDUOS SÓLIDOS NO BRASIL
}

\section{AN ANALOGY BETWEEN THE REVERSE LOGISTICS, ISO-14000 AND THE BRAZILIAN SOLID WASTE POLICY IN BRAZIL}

\section{Paula Rodrigues Vargas ${ }^{1}$; Gustavo Boni; André Luiz Emmel Silva; Elpídio Oscar Benitez Nara; Graciele Rediske; Liane Mahlmann Kipper}

Universidade de Santa Cruz do Sul, RS. Av. Independência, 2293, Santa Cruz do Sul, RS. 1Email: paulavargas@mx2.unisc.br

\begin{abstract}
RESUMO
A sociedade está mais consciente quanto aos produtos e processos ecologicamente corretos, o que faz com que a área da logística reversa, que é responsável pelo fluxo inverso dos produtos, esteja crescendo gradativamente nos últimos anos. Este artigo apresenta um estudo de caso, no que tange a logística reversa de lâmpadas fluorescentes realizado em empresa fabricante de painéis de madeira aglomerada, situada no estado do Rio Grande do Sul. O presente estudo tem como objetivo a verificação do atendimento aos requisitos descritos na Política Nacional de Resíduos Sólidos in loco, e ainda, o atendimento daqueles dispostos na norma ISO 14000, na qual a empresa busca certificação, e como estas estão envolvidas com a logística reversa. Neste trabalho se encontram a abrangência das referidas normas, bem como atuação da empresa para atendê-las.

Palavras-chave: Logística Reversa. ISO 14000. Política Nacional de Resíduos Sólidos. Lâmpadas Fluorescentes.

ABSTRACT

The society is more aware about the environmentally-friendly products and processes, which causes the area of reverse logistics which is responsible for the reverse flow of products is growing gradually in recent years. This article presents a case study in the reverse logistics of fluorescent lamps performed in company manufacturer of agglomerated wood panels, located in the State of Rio Grande do Sul. The present study aims at checking the requirements described in the national policy of solid waste on the spot, and yet, the requirements laid out in ISO 14000, in which the company seeks certification, and how these are involved with the reverse logistics. In this work are the range of the standards, as well as performance of the company to meet them.
\end{abstract}

Keywords: Reverse Logistic. ISO 14000. National Solid Waste Policy. Fluorescent Lamps. 


\section{INTRODUÇÃO}

$\mathrm{Na}$ atualidade a importância da gestão ambiental está ganhando força. Preço competitivo e qualidade não são mais os únicos aspectos considerados na compra de um produto, mas também a responsabilidade ambiental da empresa. Levando assim as organizações a buscar certificações endereçadas à gestão ambiental para atender ao mercado que está cada vez mais exigente, aumentado sua competitividade e ganhos financeiros (MARTINS e MEDEIROS, 2011).

Outro forte motivo é o fato do poder público e empresas encontrar-se fadados ao cumprimento de leis e diretrizes para a preservação ambiental. Com o aumento desta demanda, o governo federal instituiu uma política com a intenção de inibir a destinação incorreta de resíduos sólidos, e impondo a logística reversa de alguns itens em particular. Aprovada a lei 12.305/10 que institui a Política Nacional de Resíduos Sólidos (PNRS) tem por finalidade disciplinar a coleta, o destino final e o tratamento de resíduos, além de estabelecer diretrizes para reduzir a geração de lixo e combater o desperdício de materiais descartados (NATUME e SANT'ANNA, 2011; MOURÃO e SEO, 2012; JORDÃO et al., 2013). Já a logística reversa vem a somar-se a PNRS, como seu principal instrumento responsável pelo fluxo de retorno de produtos e materiais aos seus fabricantes.

Não bastasse a adequação às normas mandatórias para a preocupação das empresas privadas, há ainda para estas, o desejo das certificações em normas voluntárias para obtenção de selos "verdes", remetendo a seus produtos, serviços e processos, uma imagem politicamente correta com a preservação do meio ambiente. Isto leva sua marca a um patamar mais alto, e com valor agregado. Nesse sentido, a ISO 14000 é a norma mais difundida mundialmente (CAMPOS e MELO, 2008; ALMEIDA e SELLITTO, 2013) fazendo com que o processo produtivo seja reavaliado continuamente, refletindo na busca por procedimentos, mecanismos e padrões comportamentais menos nocivos ao meio ambiente (CAMPOS e MELO, 2008; HUDSON e ORVISKA, 2013).

No presente trabalho, foi verificada a efetivação da busca pela adequação às normas mandatórias e voluntárias em uma empresa fabricante de painéis de madeira aglomerada do Rio Grande do Sul. Também se verificou como está o processo de logística reversa destinado às lâmpadas fluorescentes, exclusivamente.

\subsection{Referencial Teórico}

\section{As lâmpadas fluorescentes}

A lâmpada fluorescente é uma lâmpada de descarga de mercúrio de baixa pressão, de seção normalmente circular, podendo ter cátodos frios ou quentes e na qual a maior parte da luz é emitida por uma camada de material fluorescente excitada pela radiação ultravioleta gerada pela descarga (ANDRÉ, 2004). A figura 1 mostra os principais constituintes de uma lâmpada fluorescente.

Lâmpadas fluorescentes são utilizadas devido ao seu baixo consumo de energia e vida útil longa em comparação com aquelas incandescentes tradicionais (CUNILL et al., 2013; SAINZ et al., 2013). Embora o mercado disponibilize outros modelos de luz artificial, as lâmpadas fluorescentes são preferencia nas instalações industriais, pois são de duas a quatro vezes mais eficientes em relação às lâmpadas incandescentes. No Brasil, o consumo cresce a cada ano, sendo que a grande quantidade de lâmpadas é oriunda de importações principalmente da China (MOURÃO e SEO, 2012) 


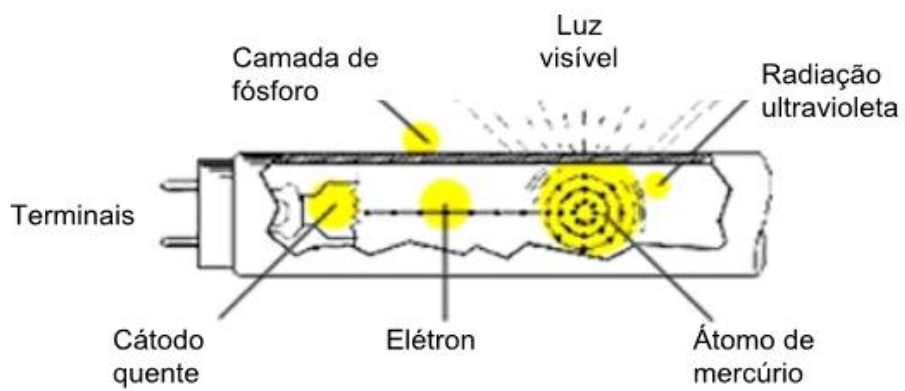

Figura 1. Principais constituintes de uma lâmpada fluorescente. Fonte: André (2004).

Esse aumento no consumo repercutiu negativamente nas questões ambientais (YANG et al., 2013), pois essas lâmpadas contêm uma variedade de metais pesados perigosos (LUCAS e EMERY, 2006; SHAO et al., 2012). A utilização destas lâmpadas e o descarte preocupa muito a sociedade pelas substâncias que elas possuem e que liberam ao se romperem (MELO Jr. et al., 2013). Existem pelo menos 12 elementos que são utilizados em lâmpadas que podem originar impactos ambientais negativos: mercúrio, antimônio, bário, chumbo, cádmio, índio, sódio, estrôncio, tálio, vanádio, ítrio e elementos de terras raras (ETR).

As lâmpadas fluorescentes não devem ser descartadas em lixo comum, nem em aterros sanitários, porque possuem mercúrio e fósforo na composição, assim sendo classificadas como contaminantes químicos. Caso tenham destino inadequado, estas podem poluir o ar, solo, lençóis freáticos, rios, chuvas, animais e o homem. Devendo ser destinadas às empresas de reciclagem devidamente autorizadas.

A gestão das lâmpadas fluorescentes descartadas, portanto, tornar-se uma questão importante (CHENG e HU, 2012; YANG et al., 2013). E para que as lâmpadas cheguem ao ponto da reciclagem é indispensável a estruturação do mercado reverso (MOURÃO e SEO, 2012).

\subsection{ISO 14000}

Para normalizar as ações das empresas preocupadas com o meio ambiente, a ISO (International Standardization Organization) criou uma série de especificações definidas na ISO 14000 para padronizar o sistema de Gestão Ambiental de uma organização (AMARAL et al., 2011; HUDSON e ORVISKA, 2013). São 28 normas abrangendo seis áreas: sistema de gestão ambiental; auditorias ambientais; avaliação de desempenho ambiental; rotulagem ambiental; aspectos ambientais nas normas de produtos; e análise do ciclo de vida do produto (CAMPOS e MELO, 2008). Sua adoção não é obrigatória, sendo normalmente ditada por pressões do mercado (SOUZA e SILVA, 1997; PRAKASH e POTOSKI, 2006), e certificadas por órgãos credenciados (AVILA e PAIVA, 2006).

A ISO 14000 tem por objetivos, estabelecer a criação, manutenção e melhoria do sistema de gestão ambiental e das áreas envolvidas em seu entorno, assim como verificar se a empresa está em conformidade (de acordo) com sua própria política ambiental e outras determinações legais; além de permitir que a empresa demonstre isso para a sociedade, através dos selos verdes obtidos, e ainda, permitir que a esta possa solicitar uma certificação/registro do sistema de gestão ambiental, por um organismo certificador (empresa que dá o certificado) externo (HUDSON e ORVISKA, 2013; HSIAO et al., 2014).

Estabelecer uma política ambiental clara e definida através da série de normas ISO 14000 contribui para que a empresa expresse o seu compromisso ambiental e formal diante da sociedade, definindo suas intenções e princípios com relação ao seu desempenho ambiental (AMARAL et al., 2011). 


\subsection{Política Nacional de Resíduos Sólidos (PNRS)}

A Política Nacional de Resíduos Sólidos - PNRS (Lei no 12.305/2010), regulamentada em dezembro de 2010 pelo decreto $\mathrm{n}^{\mathrm{o}} 7.404$, tem a finalidade de extinguir lixões, conduzindo resíduos reutilizáveis para usinas de reciclagem e os que não possuem mais esta possibilidade, para aterros sanitários devidamente preparados para este fim, conforme normas e legislações vigentes.

De acordo com o artigo 33 da PNRS os fabricantes, importadores, distribuidores e comerciantes de alguns produtos de elevada periculosidade serão obrigados a desenvolver sistemas que permitam a coleta seletiva dos resíduos contaminados e o seu encaminhamento às indústrias onde serão reinseridos na cadeia produtiva ou, alternativamente, dispostos em locais adequados (NATUME e SANT'ANNA, 2011; QUINTIERE, 2012). Com prazo de implantação até 2014, inicialmente engloba cinco grupos de produtos: agrotóxicos, seus resíduos e embalagens, assim como outros produtos cuja embalagem, após o uso, constitua resíduo perigoso; pilhas e baterias; pneus; óleos lubrificantes, seus resíduos e embalagens; lâmpadas fluorescentes, de vapor de sódio e mercúrio e de luz mista e produtos eletroeletrônicos e seus componentes.

A PNRS esta inserida, portanto, em uma rede de articulação de forças, de refração de interesses e também de transformação que permite a constituição de instrumentos específicos e estratégias objetivas capazes de incorporar mudanças nas organizações e, consequentemente, induzir mudanças na economia e na sociedade (JORDÃ O, 2013).

A PNRS apresenta a logística reversa como uma das principais ferramentas de gerenciamento de resíduos sólidos aplicando-se às pessoas jurídicas ou físicas, de direito privado ou público, sejam estas responsáveis, direta ou indiretamente, pela produção dos resíduos (SILVA et al., 2012b).

\subsection{Logística Reversa}

A Logística Reversa é um segmento da logística responsável pelo retorno de produtos aos fabricantes para o reaproveitamento dos componentes desse produto ou, pelo menos, para que lhes seja dado um destino ambientalmente correto (SRIVASTAVA, 2008; SILVA et al., 2012a).

Pertence a uma área da logística empresarial que planeja, opera e controla o fluxo e as informações logísticas correspondentes, do retorno dos bens de pós-venda e de pós-consumo ao ciclo de negócios ou ciclo produtivo. Tudo por meio dos canais de distribuição reversos, agregandolhes valor de diversas naturezas: econômico, ecológico, legal, logístico, de imagem corporativa, entre outros (LEITE, 2009). Entre os propulsores da logística reversa está o potencial de recuperação de valor a partir de produtos usados, as legislações mais rígidas, a crescente conscientização do consumidor e a responsabilidade das empresas perante o meio ambiente (FERRER e AYRES, 2000; RAVI e SHANKAR, 2005; POKHAREL e MUTHA, 2009).

Neste sentido, a PNRS, colocou a obrigação da logística reversa de lâmpadas fluorescentes. Em linhas gerais, a ideia é que do mesmo jeito que todo mundo se esforça para vender (importadores, fabricantes, distribuidores e comerciantes) e para comprar (consumidor), devem se esforçar um pouco para descartar. Fazendo o sentido inverso, as lâmpadas podem voltar para a origem e importadores e fabricantes serão responsabilizados por dar o destino correto (MANCINI, 2013).

\section{MATERIAIS E MÉTODOS}

A metodologia utilizada foi a pesquisa descritiva que é aquela em que se observa, registra, analisa e correlaciona fatos ou fenômenos sem manipulá-los. Quanto ao meio, a pesquisa foi a bibliográfica e de campo onde se obteve toda a fundamentação teórica a partir de livros, dissertações, jornais, redes eletrônicas de acesso ao público em geral para que se pudesse obter o 
levantamento do estado da arte do tema e também para fundamentação teórica, e após, foi feito uma pesquisa para coleta de fatos e dados em campo. A coleta de fatos e dados foi efetuada em contato direto com a empresa, onde foi verificado o processo de gestão e manutenção da coleta seletiva de lampadas fluorescentes, bem como sua destinação final a prestadores de serviço homologados.

\section{RESULTADOS E DISCUSSÃO}

A empresa em estudo é uma das maiores empresas produtoras de painéis de madeira industrializada do país, sendo que seu modelo de negócio combina a prática dos princípios da sustentabilidade nas suas operações e nas comunidades onde atua. Possui acompanhamento às legislações, o monitoramento dos riscos, a preservação do meio ambiente e a responsabilidade social. Desde 2004, de forma voluntária, a empresa é certificada pela ISO 14000 e a partir de 2012 adaptou-se a mandatória Lei 12.305 (PNRS). Suas áreas industriais adotam um Sistema de Gestão Ambiental que permite o acompanhamento do desempenho no tratamento de efluentes e na correta destinação de resíduos sólidos, além de ações voltadas para a redução de emissões atmosféricas e redução do consumo de energia elétrica. Todo resíduo gerado pela empresa é monitorado periodicamente (Tabela 1).

Tabela 1 - Resíduos gerados, sua origem no processo e quantidades destinadas.

\begin{tabular}{cccccc}
\hline $\begin{array}{c}\text { Resíduo } \\
\text { Classe I }\end{array}$ & $\begin{array}{c}\text { Momenclatura } \\
\text { Fesíduos sólidos on- } \\
\text { line) }\end{array}$ & SIGCORS & Origem & $\begin{array}{c}\text { Quantidade } \\
\text { (ano) }\end{array}$ & $\begin{array}{c}\text { Unidade } \\
\text { de medida }\end{array}$ \\
\hline Resíduo EPI & $\begin{array}{c}\text { Equipamento de } \\
\text { proteção individual - } \\
\text { EPI }\end{array}$ & X014 & $\begin{array}{c}\text { Pontos diversos } \\
\text { das áreas } \\
\text { produtivas e } \\
\text { administrativas }\end{array}$ & 5 & $\mathrm{~m}^{2}$ \\
\hline $\begin{array}{c}\text { Resíduo de } \\
\text { lâmpadas } \\
\text { fluorescentes }\end{array}$ & $\begin{array}{c}\text { Lâmpadas } \\
\text { fluorescentes usadas } \\
\text { (vapor de mercúrio e } \\
\text { sódio) }\end{array}$ & K00106 & $\begin{array}{c}\text { Pontos diversos } \\
\text { das áreas } \\
\text { produtivas e } \\
\text { administrativas }\end{array}$ & 700 & Un. \\
\hline $\begin{array}{c}\text { Material } \\
\text { contaminado } \\
\text { com óleo }\end{array}$ & $\begin{array}{c}\text { Material contaminado } \\
\text { com óleo }\end{array}$ & F0031 & $\begin{array}{c}\text { Manutenção de } \\
\text { equipamentos e } \\
\text { veículos }\end{array}$ & 60 & Ton. \\
\hline $\begin{array}{c}\text { Óleo } \\
\text { lubrificante } \\
\text { usado }\end{array}$ & $\begin{array}{c}\text { Óleo lubrificante } \\
\text { usado (contaminado) }\end{array}$ & F0030 & $\begin{array}{c}\text { Manutenção de } \\
\text { equipamentos e } \\
\text { veículos }\end{array}$ & 56 & Ton. \\
\hline $\begin{array}{c}\text { Resídiuo } \\
\text { Ambulatorial }\end{array}$ & $\begin{array}{c}\text { Resíduo de Serviço de } \\
\text { Saúde (Material } \\
\text { Infecto, Agulhas, } \\
\text { outros) }\end{array}$ & D0040 & Ambulatório \\
médico & 0,05 & Kg \\
\hline
\end{tabular}

A logística observada na empresa mostrou que, depois de substituídas, as lâmpadas são guardadas em um local apropriado e devidamente identificado, dentro da área fabril até obter uma quantidade significativa. Depois de atingida essa quantidade, as lâmpadas são enviadas a uma central de resíduos localizada na empresa, e quantificadas para o setor de segurança do trabalho. A Figura 2 mostra o ponto de coleta seletiva na área fabril. 


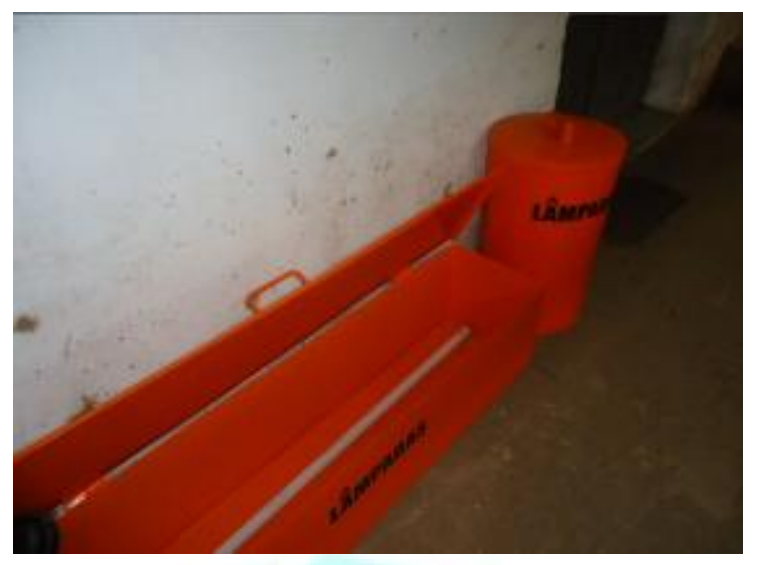

Figuras 2. Ponto de coleta seletiva na área fabril

$\mathrm{Na}$ central de resíduos ocorre o processo de controle. Inicialmente as lâmpadas recebem a classificadas de risco de acordo com suas características ( Resíduo Perigoso Classe I) e inicia-se o processo de segregação. São separados de acordo com o seu tamanho, contabilizadas e embaladas. As lâmpadas rompidas são dispostas em um recipiente separado (tonéis metálicos identificados na cor laranja), onde recebem identificação e posteiror pesagem. Para a segurança dos funcionários, a empresa disponibiliza os EPIs (Equipamento de Proteção Individual) para a realização dessa atividade, sendo eles: luvas, óculos, mascara respiratória e avental de PVC. No local também está disponibilizado a FISPQ (Ficha de Informações de Segurança do Produto Químico), para garantir a segurança do colaborador em casos de algum acidente com as lâmpadas. A Figura 3 mostra as lâmpadas já devidamente acondicionadas em caixas maiores aguardando destino final.

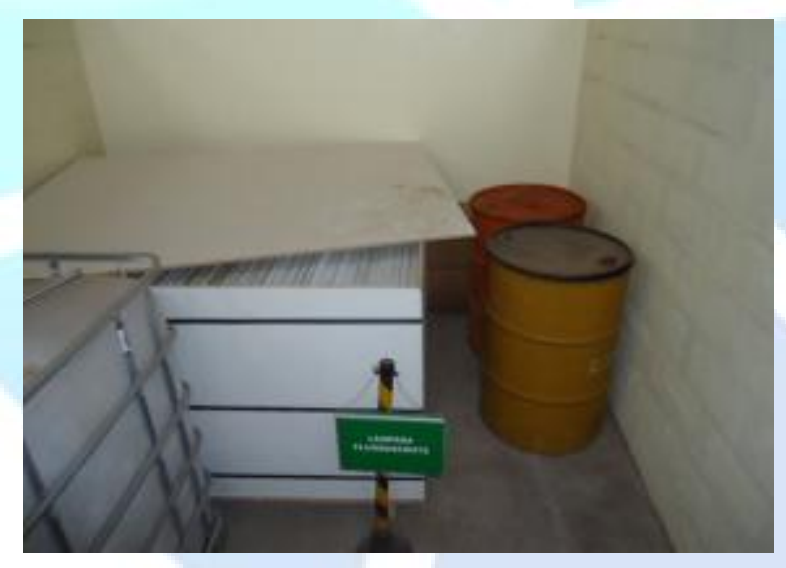

Figura 3. Armazenagem aguardando destino final

Para destinação e transporte dos resíduos gerados, a empresa utiliza empresas homologadas conforme seu procedimento interno de homologação de fornecedores relacionados à gestão de resíduos sólidos. Para tanto, a empresa possui grupo de homologação de fornecedores/receptores de resíduos que conta com técnicos de diversas áreas de formação, atuação e função e cujas atividades seguem procedimentos internos. A coleta dos resíduos de lâmpadas é feita de duas a três vezes por ano.

O supervisor de meio ambiente da empresa é responsável pela correta destinação no que diz respeito à documentação legal necessária, reporte ao órgão ambiental e demais demandas legais que se façam necessárias. Cada resíduo é destinado a uma empresa credenciada e certificada para atuar como tal, assim como o serviço de transporte. A Tabela 2 mostra o resíduo, a empresa responsável pela coleta e transporte e a empresa responsável pelo destino final. 
Tabela 2 - Resíduo, empresa de coleta e destinacao ao resíduo

\begin{tabular}{|c|c|c|}
\hline $\begin{array}{l}\text { Resíduo } \\
\text { ( Classe I ) }\end{array}$ & $\begin{array}{c}\text { Transportador } \\
\text { ( empresa ) }\end{array}$ & $\begin{array}{c}\text { Destino Final } \\
\text { ( empresa ) }\end{array}$ \\
\hline Resíduo EPI & $\begin{array}{l}\text { Transmbiental } \\
\text { Serviços } \\
\text { Ambientais Ltda }\end{array}$ & $\begin{array}{c}\text { Proamb - Soluções } \\
\text { Ambientais, Aterro } \\
\text { Industrial, Acessoria } \\
\text { Ambientla e Projetos }\end{array}$ \\
\hline $\begin{array}{l}\text { Resíduo de lâmpadas } \\
\text { fluorescentes }\end{array}$ & $\begin{array}{l}\text { Apliquim Brasil } \\
\text { Recicle }\end{array}$ & Apliquim Brasil Recicle \\
\hline $\begin{array}{l}\text { Material contaminado com } \\
\text { óleo }\end{array}$ & - & $\begin{array}{l}\text { Aguardando } \\
\text { homologação }\end{array}$ \\
\hline Óleo lubrificante usado & $\begin{array}{c}\text { Industria } \\
\text { Petroquímica do } \\
\text { Sul Ltda }\end{array}$ & $\begin{array}{l}\text { Industria Petroquímica } \\
\text { do Sul Ltda }\end{array}$ \\
\hline Resídiuo Ambulatorial & - & $\begin{array}{l}\text { Aguardando } \\
\text { homologação }\end{array}$ \\
\hline
\end{tabular}

Dada a periculosidade do resíduo, o transporte só é liberado após a emissão do MTR (Manisfesto de Transporte de Resíduo), bem como preenchimento da FISPQ, e a obrigatoriedade do cadastro na FEPAM do meio de transporte do resíduo. Áqueles, que porventura tiverem destinação final para fora do estado de origem deverão obter previamente a respectiva Autorização de Remessa, perante o Órgão Estadual Ambiental.

A ISO 14000 tem em seus requisitos, que a empresa cumpra suas obrigatoriedades legais aplicáveis ao seu processo e sendo a PNRS esta obrigação para a empresa, a certificação só se dá e se mantém enquanto houver a adequação a esta legislação e outras demais de mesmo âmbito (ambiental). Pelo descrito na norma, ainda são requisitadas as devidas documentações para comprovação de destinação correta dos resíduos contemplados, bem como certificação e adequação deste local de destino.

A maior dificuldade encontrada foi na seleção e aprovação conforme normas internas e adequadas à legislação do fornecedor do serviço de destinação, visto que para cada tipo de resíduo tem de ser desenvolvido um prestador diferente. Além desta dificuldade comentada, houve muitas oportunidades de treinamento das equipes para conscientização da destinação correta dos resíduos que só surtiram efeito após penalidades dos setores em auditorias dentro das lixeiras. A pontuação e premiação das auditorias, incitando uma competição pelo setor com melhor desempenho foi a ação com melhor resultado encontrada para que o chão de fábrica aderisse à coleta seletiva e à destinação correta dos resíduos.

\section{CONCLUSÕES}

Tomando como base os procedimentos operacionais da empresa referente ao plano de gerenciamento de resíduo sólido, certificação na ISO 14000, norma que define os procediments a fim de estabelecer um Sistema de Gestão Ambiental, assegura-se, portanto, que os procedimentos adotados pela empresa, embora este não seja considerada de fato uma logística reversa e sim uma política, uma vez que os resíduos gerados não retornam diretamente ao fornecedor e sim à uma empresa legalmente habilitada, é considerada correta e aplicável. A empresa atua de forma qualificada e certificada, para o objeto deste artigo (lâmpadas fluorescentes), bem como para outros 
resíduos amparados pelas legislações vigentes, incluindo legislações federal, estadual e municipal.

Conclui-se, portanto, que a logística reversa e a ISO 14000 estão a trabalho da Politica Nacional de Resíduos Sólidos, pois auxiliam que esta seja efetiva e eficaz, bem como dê retorno aos investimentos da empresa com a conquista do selo verde. Percebe-se também o desejo da empresa de ter em sua marca, a responsabilidade social e a preservação do meio ambiente como fatores indispensáveis aos processos industriais.

\section{REFERÊNCIAS}

ALMEIDA, T.S.M. de; SELLITTO, M. A. Avaliação do desempenho ambiental de uma instituição pública de ensino técnico e superior. Produção [online]. Florianópolis, v. 23, n.3, p. 625-636, 2013.

AMARAL, A.C. do.; LEITE, D.; CHEN, H.; SUNG, J.; LUCAS, R. Criando valor para o acionista através da certificação ISO 14000: Um estudo múltiplo de casos. Revista Portuguesa e Brasileira de Gestão [online]. Lisboa, v.10, n.1-2, p. 37-47, 2011.

ANDRÉ, A.S. Sistemas eletrônicos para lâmpadas de vapor de sódio de alta pressão. Tese (Doutorado em Engenharia Elétrica)- Departamento de Engenharia Elétrica, Universidade Federal de Santa Catarina. Florianópolis, 2004. 134p.

AVILA, G.J.; PAIVA, E.L. Processos operacionais e resultados de empresas brasileiras após a certificação ambiental ISO 14001. Gest. Prod. [online]. São Carlos, v.13, n.3, p. 475-487, 2006.

CAMPOS, L.; MELO, D. Indicadores de desempenho dos Sistemas de Gestão Ambiental (SGA): uma pesquisa teórica. Produção. São Paulo, v. 18, n. 3, p. 540-555, 2008.

CHENG, H.; HU, Y. Mercury in municipal solid waste in China and its control: a review. Environ Sci Technol. Washington, v. 46, p. 593-605, 2012.

CUNILL, J.; SAINZ, L.; MESAS, J.J. Neutral conductor current in three-phase networks with compact fluorescent lamps. Electric Power Systems Research. Lausanne, v. 103, p. 70-77, 2013.

FERRER, G, AYRES, R. The impact of remanufacturing in the economy. Ecological Economics. Nova York, v. 32, n. 3, p. 413-429, 2000.

HSIAO, T.Y.; CHUANG, C.M.; KUO, N.W.; YU, S.M.F. Establishing attributes of an environmental management system for green hotel evaluation. International Journal of Hospitality Management. Nova York, v.36, p. 197-208, Jan 2014.

HUDSON, J.; ORVISKA, M. Firms' adoption of international standards: One size fits all? Journal of Policy Modeling. Nova York, v. 35, n. 2, p. 289-306, 2013.

JORDÃO, A.A.; SALTORATO, P.; CUNHA, R.N.; CALREGARI, C.H. Meio ambiente e sociedade: a conformação da política nacional de resíduos sólidos no brasil e suas implicações. In: XX Simpósio de Engenharia de Produção, Anais... Bauru, 2013.

LEITE, P.R. Logística reversa: meio ambiente e competitividade. 2. ed. São Paulo: Pearson, 2009. 240p. 
LUCAS, A.; EMERY, R. Assessing occupational mercury exposures during the on-site processing of spent fluorescent lamps. J. Environ. Health. Denver, v. 68, n. 30-4, p. 40-45, 2006.

MANCINI, S.D. O lado B das lâmpadas fluorescentes. 2013, Disponível em:

<http://www.cruzeirodosul.inf.br/materia/485298/o-lado-b-das-lampadas-fluorescentes> Acesso em: 22 jan. 2014.

MARTINS, G.C; MEDEIROS, G.A. de. Aspectos e Benefícios da Implantação da Certificação ISO 14001 em empresa do setor de Logística da região metropolitana de Campinas. Holos

Environment. Rio Claro, v.11, n. 2, p. 114, 2011.

MELO Jr, T.A.; DÂNDARO, F.; AMBROSETO, G.; TABAH, J. Estudo de caso: coleta e logística reversa para lâmpadas fluorescentes no município de Franca, SP. Revista Eletrônica em Gestão, Educação e Tecnologia Ambiental - REGET. Santa Maria, v. 10, n. 10, p. 2091-2101, 2013.

MOURÃO, R.F.; SEO, E.S.M. Logística reversa de lâmpadas fluorescentes. Revista InterfacEHS. São Paulo, v.7, n.3, 2012.

NATUME, R.Y.; SANT'ANNA, F.S.P. Resíduos Eletroeletrônicos: Um Desafio Para o Desenvolvimento Sustentável e a Nova Lei da Política Nacional de Resíduos Sólidos. 3rd International Workshop Advances in Cleaner Production, São Paulo - Brazil - May - 2011.

POKHAREL, S.; MUTHA, A. Perspectives in reverse logistics: a review. Resources, Conservation and Recycling. Nova York, v. 53, n. 4, p. 175-182, 2009.

PRAKASH, A.; POTOSKI, M. Racing to the bottom? Trade, environmental governance, and ISO 14001. American Journal of Political Science. Michigan, v. 50, n. 2, p. 350-364, 2006.

QUINTIERE, M.M.R. A PNRS e as lâmpadas de mercúrio. 2012. Disponível em: <https://www.portaleducacao.com.br/educacao/artigos/19457/a-pnrs-e-as-lampadas-de-mercurio>. Acesso em 21 jan. 2014.

RAVI, V.; SHANKAR R. Analysis of interactions among the barriers of reverse logistics. Technological Forecasting and Social Change. Nova York, v. 72, n. 8, p. 1011-1029, 2005.

SAINZ, L.; CUNILL, J.; MESAS, J.J. Parameter estimation procedures for compact fluorescent lamps with electronic ballasts. Electric Power Systems Research. Lausanne, v. 95, p. 77-84, 2013.

SHAO, D.D.; WU, S.C.; LIANG, P.; KANG, Y.; FU, W.J.; ZHAO, K.L.; CAO, Z.H.; WONG, M.H. A human health risk assessment of mercury species in soil and food around compact fluorescent lamp factories in Zhejiang Province, PR China. Journal of Hazardous Materials. Nova York, v. 221-222 p. 28-34, 2012.

SILVA, A.L.E.; MORAES, J.A.R.; MACHADO, E.L. Proposta de um programa de P+L como ferramenta para promoção da gestão ambiental: Estudo de caso. Tecno-Lógica, Santa Cruz do Sul, v. 16, n.1, p. 40-47, jan./jun. 2012a. 
SILVA, A.L.E.; REHBEIN, A.E.; BENCKE, D.B.; REDISKE, G.; GERHARD, G. Aplicação da logística reversa para medicamentos em desuso: estudos de caso. In: XIX Simpósio de Engenharia de Produção, Anais... Bauru, 2012b.

SOUZA, M.; SILVA, R. A geração de resíduos industriais e sua destinação final. In: Encontro Nacional de Engenharia de Produção - ENEGEP, 1997, Gramado. Anais... Gramado: ABEPRO, 1997.

SRIVASTAVA, S.K. Network design for reverse logistics. The International Journal of Management Science. Philadelphia, v.36, p.535-548, 2008.

YANG, F.; KUBOTA, F.; BABA, Y.; KAMIYA, N; GOTO, M. Selective extraction and recovery of rare earth metals from phosphor powders in waste fluorescent lamps using an ionic liquid system. Journal of Hazardous Materials. Nova York, v.254-255, p. 79-88, 2013. 